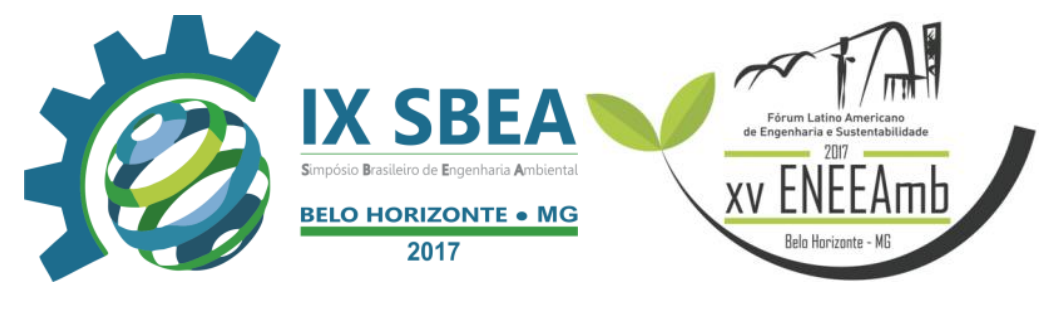

RECURSOS HÍDRICOS E SANEAMENTO

\title{
ELETROFLOCULAÇÃO PARA O REUSO DA ÁGUA NA INDÚSTRIA TÊXTIL
}

Cristiele Costa de Souza - tielle09@ hotmail.com

Centro Universitário de Belo Horizonte

Ana Leticia Martins dos Santos- analeticiams11@ yahoo.com.br

Centro Universitário de Belo Horizonte

Fernanda Alves dos Santos - fernandaalves_13@ hotmail.com

Centro Universitário de Belo Horizonte

Janaína Gessica Mendes Moreira - janainagessica@ yahoo.com.brl

Centro Universitário de Belo Horizonte

Lucas da Silva Ferreira - lucas.bio.mar@hotmail.com

Centro Universitário de Belo Horizonte

Miriam Cristina da Silva - miriam.palowa@ hotamail.com

Centro Universitário de Belo Horizonte 


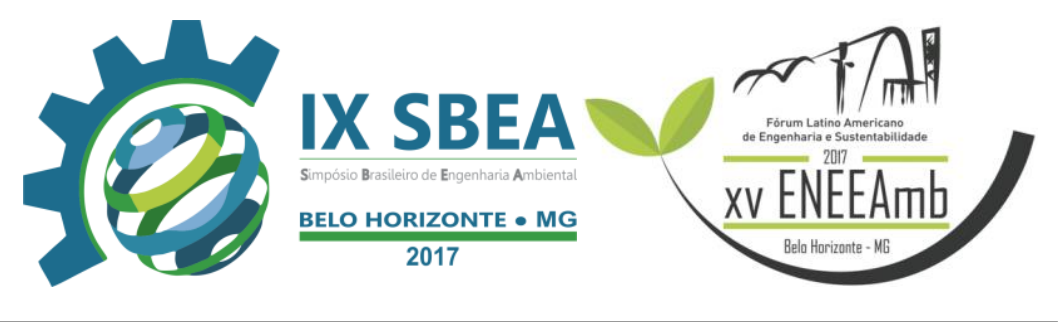

\section{RESUMO}

A água é um recurso natural de grande importância aos seres vivos. No que se refere ao consumo da indústria, o setor têxtil consome aproximadamente $15 \%$ da água. A tinturaria e o acabamento são as etapas de maior potencial contaminante do processo produtivo têxtil se comparadas com a fiação e a tecelagem. Os produtos químicos utilizados na indústria têxtil compreendem compostos inorgânicos, polímeros e produtos orgânicos. A eletrofloculação trata-se de um processo eletroquímico baseado na geração de gases (geralmente $\mathrm{O} 2$ ou H2) as quais substituem os aditivos floculantes. Para realização da técnica de eletrofloculação coletou-se $5 \mathrm{~L}$ do efluente em uma Indústria Têxtil localizada em Belo Horizonte, Minas Gerais. Com isso os resultados mostraram a eficiência do processo de eletrofloculação no tratamento de efluentes têxteis, considerando que a $(\mathrm{EF})$ gera o agente coagulante que, por sua vez, formará os flocos do material particulado e ao mesmo tempo realiza a flotação do resíduo gerado, esse processo mostra-se bastante simples e de baixo custo

Palavras-chave: Eletrofloculação, Indústria têxtil, Reuso, Água.

\section{INTRODUÇÃO/OBJETIVO}

A água é um recurso natural de grande importância aos seres vivos e para os humanos. Além do consumo, também é utilizada para a economia, através da irrigação, navegação e produção de energia elétrica. Por ser um recurso de fácil acesso e disponibilidade, por muitos anos seu consumo ocorreu de maneira equivocada e despreocupada, resultando na poluição e no desperdício das águas do planeta principalmente da água doce, encontrada em menor quantidade e a mais necessária aos seres vivos.

O aumento da preocupação com o uso dos recursos hídricos resultou na valorização da água potável como bem de consumo e, frente a este potencial de escassez, órgãos ambientais têm aplicado legislações com maior rigor.

De acordo com Couto et al. (2004), o desenvolvimento sustentável deve promover a conservação dos recursos naturais, serem tecnicamente apropriado, 


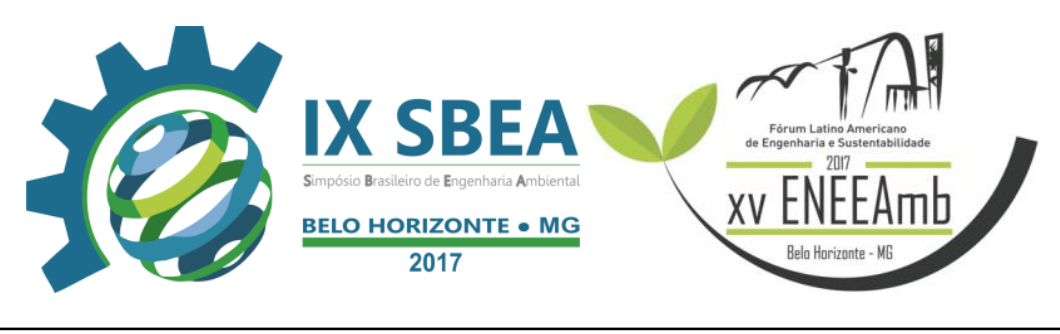

economicamente viável e socialmente aceitável, de tal forma que permita satisfazer as necessidades de crescimento de um país.

No que se refere ao consumo da indústria, o setor têxtil consome aproximadamente $15 \%$ da água. O potencial contaminante da indústria têxtil, em sua totalidade, é considerado médio, sendo a tinturaria e o acabamento as etapas do processo produtivo têxtil mais contaminante se comparado com a fiação e a tecelagem (TOLEDO, 2004).

De acordo com MORAN et al. (1997) e TALARPOSHTI et al. (2001), as indústrias têxteis possuem uma das mais altas cargas poluidoras em seu efluente, devido às variações em seus processos e produtos utilizados, o que torna seus efluentes um composto complexo.

O setor industrial têxtil é caracterizado por um elevado consumo de água, gerando um grande volume de efluentes líquidos, além de ter uma concentração elevada de matéria orgânica (MELO 2005; SCHNEIDERS, 2011). São necessários aproximadamente $80 \mathrm{~L}$ de água para produzir $1 \mathrm{~kg}$ ordem de $150 \mathrm{~L}$, sendo que $80 \%$ deste volume são descartados como efluente e apenas $12 \%$ do total compõem as perdas por evaporação, como os mencionados por Immich (2006). Segundo Hassemer (2006), na produção de tecido de algodão, por exemplo, o consumo de água pode variar de 100 a 300L.kg-1 de tecido.

Outra característica é a mudança constante do corante utilizado no processo produtivo, o que por consequência modifica as características químicas e físicas do efluente gerado, alterando a concentração da demanda química de oxigênio (DQO) e pH (CERQUEIRA et al., 2009). Nesse sentido, Kunz et al. (2002) afirmam que os efluentes têxteis possuem em sua composição quantidade considerável de corantes que não se fixam na fibra têxtil durante o processo de tingimento do tecido, o que altera consideravelmente a qualidade da água do curso hídrico receptor.

Segundo Cerqueira (2006) muitos são os métodos utilizados no tratamento de efluentes industriais e estes podem ser divididos em três categorias: químicos, físicos e biológicos. Os métodos de tratamento estão diretamente relacionados ao tipo de efluente gerado, ao controle operacional da atividade industrial e das características da água utilizada. Devido à dificuldade de fazer o tratamento dos efluentes das indústrias têxteis, 


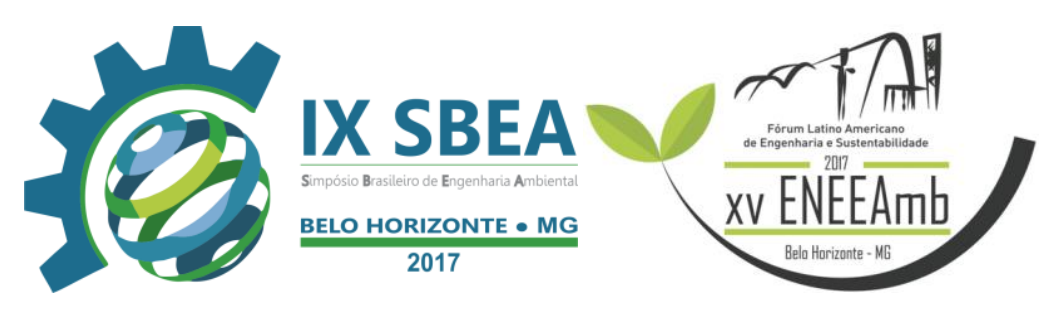

novas tecnologias têm sido investigadas. Sendo assim, Cerqueira (2006) afirma que "neste contexto, a eletrofloculação surge como uma técnica promissora, devido a sua eficiência e possibilidade de reuso da água".

Na tecnologia de eletrofloculação não ocorre à adição de floculantes, o que evita a formação de lodo residual. Trata-se de um processo eletroquímico baseado na geração de gases (geralmente $\mathrm{O} 2 \mathrm{ou} \mathrm{H} 2$ ) as quais substituem os aditivos floculantes. O processo consiste em quatro etapas, sendo elas:

(1) geração de pequenas bolhas de gás;

(2) contato entre as bolhas e as partículas em suspensão;

(3) adsorção das pequenas bolhas de gás na superfície das partículas e;

(4) ascensão do conjunto partículas/bolhas para a superfície.

Então, toda a matéria em suspensão é eletroflotada, provocando o clareamento do líquido tratado. Na superfície, forma-se uma camada de espuma que contém as partículas flotadas que são facilmente removidas (PASCHOAL; FILHO, 2005).

O objetivo do trabalho foi encontrar a região ótima das condições operacionais da técnica de eletrofloculação aplicada ao efluente líquido de uma indústria têxtil, verificando a condutividade elétrica, a intensidade da corrente e a densidade química de oxigênio (DQO).

O tema eletrofloculação é um método de reaproveitamento da água em processos industriais e ainda está sendo estudado para aplicação. Esta técnica visa também diminuir os impactos ambientais em cursos d'água de forma a auxiliar o reaproveitamento da água na indústria. $\mathrm{O}$ que gera economia a empresa e beneficia $\mathrm{o}$ meio ambiente.

\section{METODOLOGIA}

Para o processo da eletrofloculação coletou-se 5L do efluente em uma Indústria Têxtil localizada em Belo Horizonte, Minas Gerais o qual foi armazenado sob refrigeração para posteriores análises, visando manter as características físico-químicas da amostra.

Realizou-se um primeiro experimento para a obtenção de um "ponto ideal” do reagente Cloreto de Sódio ( $\mathrm{NaCl}$ ), ou seja, 1g/100ml, para implementação no experimento final, 


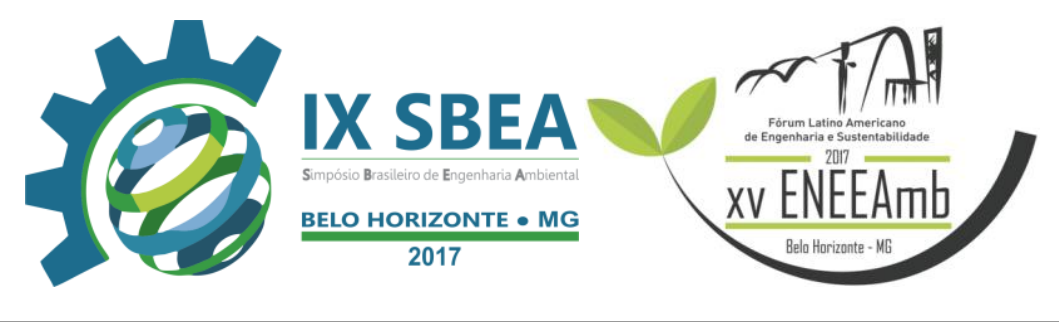

para que se realize análises do efluente bruto e do efluente tratado (eletrofloculado) para fins de avaliação da eficiência dos eletrodos utilizados na presente técnica.

Com este experimento preliminar definiu-se que a quantidade de $\mathrm{NaCl}$ deverá ser de 10 gramas.

Para o teste final da eletrofloculação foram utilizados $1 \mathrm{~L}$ do efluente bruto (Figura 1) para cada recipiente, misturando $10 \mathrm{~g}$ de $\mathrm{NaCl}$ a solução, com o auxílio de um bastão de vidro. Para cada recipiente foram utilizados 2 eletrodos de alumínio (dimensões com $100 \mathrm{~mm}$ de comprimento $50 \mathrm{~mm}$ de largura e $0,6 \mathrm{~mm}$ de espessura) e outros 2 de ferro ( dimensões de $150 \mathrm{~mm}$ de comprimento e $0,2 \mathrm{~mm}$ de largura) e em seguida aplicou-se uma voltagem com auxílio de uma bateria e uma corrente elétrica medido pelo amperímetro, de acordo com a tabela 1.

Após o procedimento de eletrofloculação, filtrou-se o efluente, utilizando um funil de vidro e um filtro de papel e observou-se a aparência após a filtração.

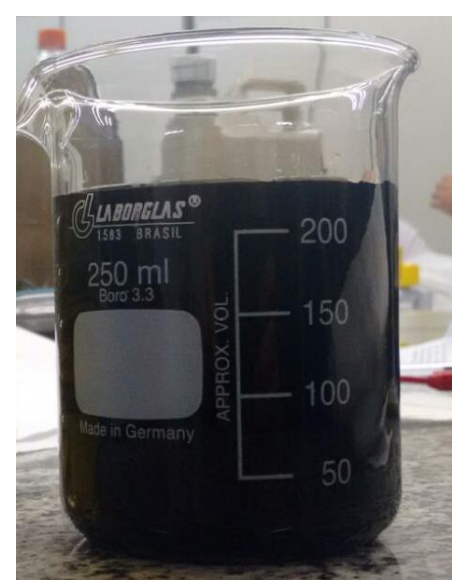

Figura 1: Efluente Bruto

Tabela 1 - Parâmetros aplicados

\begin{tabular}{|c|c|c|c|c|}
\hline Amostras & $\begin{array}{c}\text { Tensão } \\
(\mathbf{V})\end{array}$ & $\begin{array}{c}\text { Amperímeto } \\
(\mathbf{A})\end{array}$ & $\begin{array}{c}\text { Potência } \\
(\mathbf{W})\end{array}$ & Tempo \\
\hline $\begin{array}{c}\text { Alumínio } \\
(1)\end{array}$ & $5.6 \mathrm{~V}$ & $2.11 \mathrm{~A}$ & $11,82 \mathrm{~W}$ & $\begin{array}{c}4 \mathrm{~h} \\
30 \mathrm{~min}\end{array}$ \\
\hline Ferro (2) & $16.8 \mathrm{~V}$ & $2.87 \mathrm{~A}$ & $48,2 \mathrm{~W}$ & $\begin{array}{c}4 \mathrm{~h} \\
30 \mathrm{~min}\end{array}$ \\
\hline
\end{tabular}




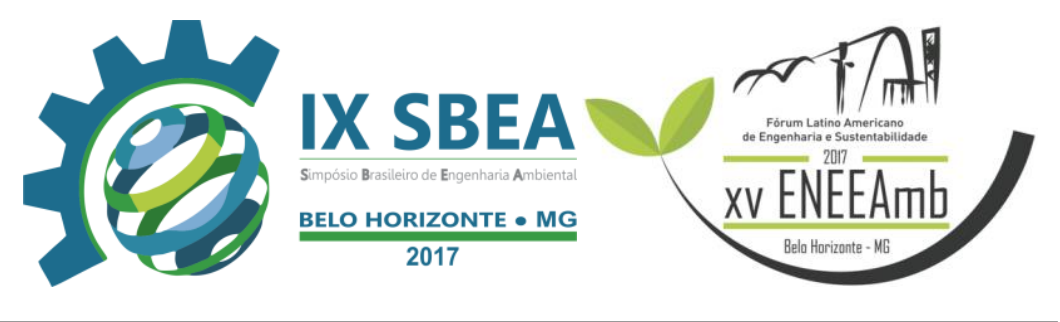

\section{RESULTADOS E DISCUSSÃO}

Apresentar os dados obtidos, análise e discussão dos resultados. Caso haja necessidade d A tabela 2 apresenta os parâmetros do efluente in natura. Contudo, a resolução do CONAMA 357/05 (BRASIL, 2005) não estabelece valores da DQO para lançamento de águas residuais, que é um importante parâmetro para verificar a qualidade da água (THEBALDI, 2011).

Tabela 2

\begin{tabular}{|c|c|}
\hline Parâmetro & Valores \\
\hline Turbidez & 110 NTU \\
\hline $\mathrm{pH}$ & 8,49 \\
\hline
\end{tabular}

Observou-se que, ao contato dos eletrodos de alumínio (amostra 1) e ferro (amostra 2) ocorreu uma mudança do parâmetro cor e a junção do particulado formando uma camada superficial, como mostra as figuras 2 e 3.

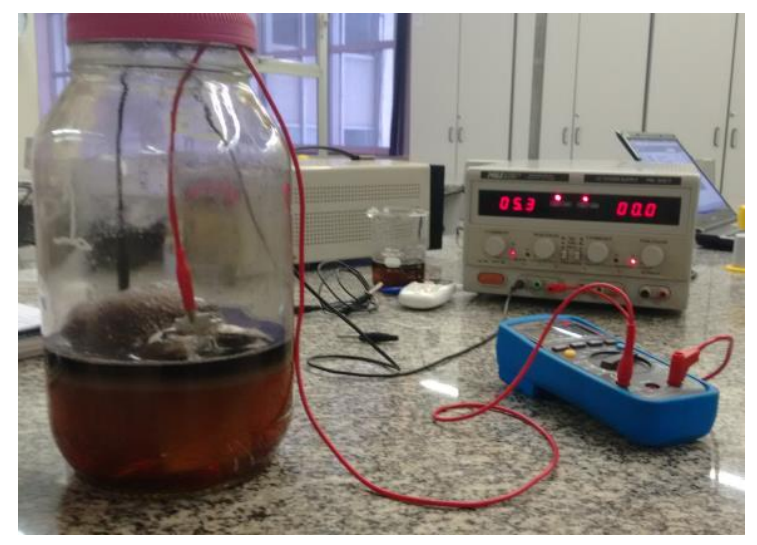

Figura 2- Eletrodo de alumínio. 

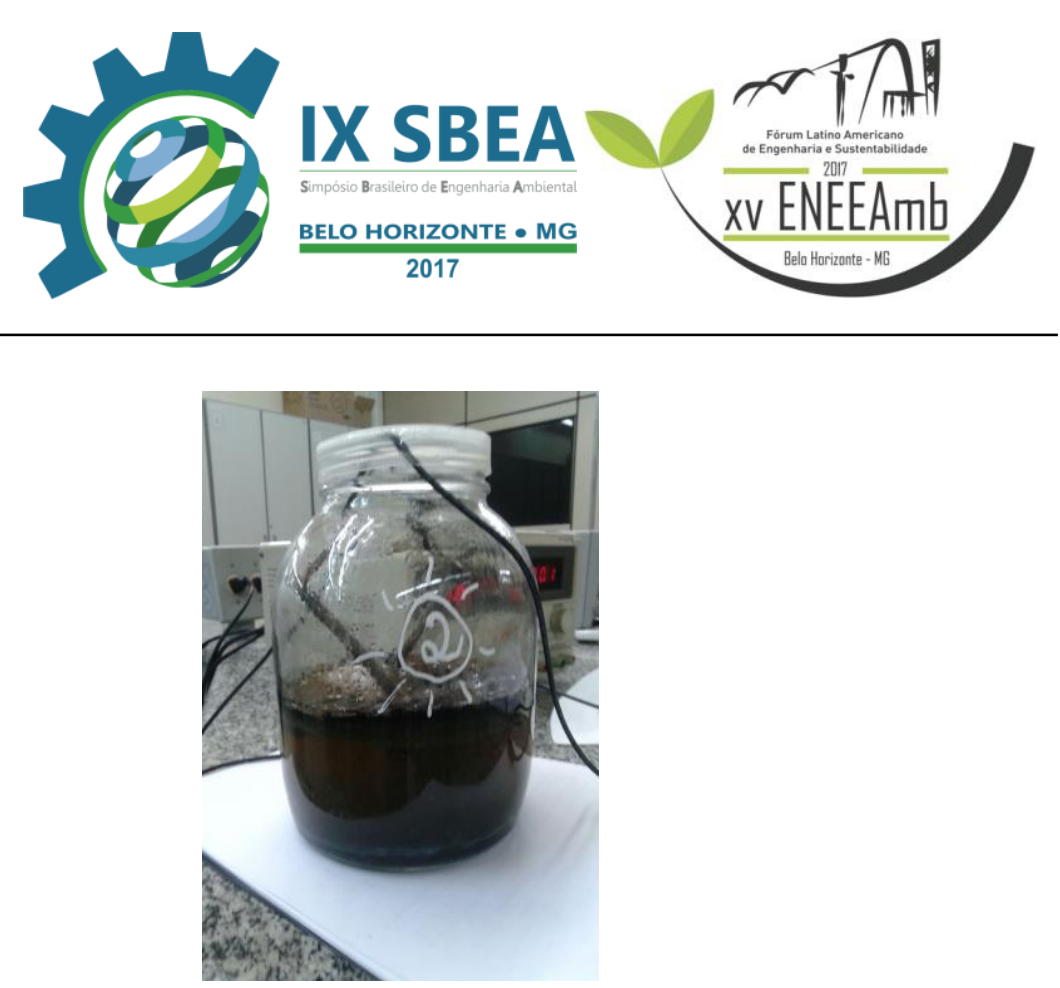

Figura 3 - Eletrodo de Ferro

Após o procedimento da eletrofloculação e filtração as amostras apresentaram uma notável redução de sua coloração inicial (Figura 4), sendo assim foram observados os parâmetros de turbidez, pH e massa (Tabela 3).

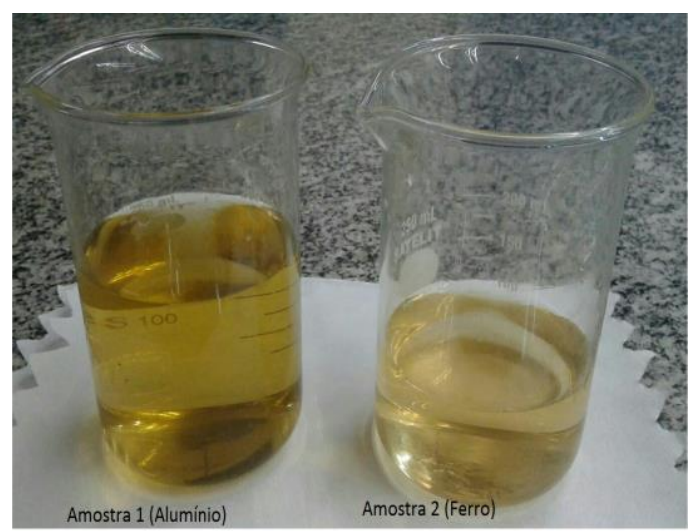

Figura 4 - Amostra pós-filtração

Tabela 3

\begin{tabular}{|c|c|c|}
\hline Parâmetro & Amostra 1 & Amostra 2 \\
\hline $\mathrm{pH}$ & 11,75 & 12,95 \\
\hline Turbidez & $0,59 \mathrm{NTU}$ & $0,75 \mathrm{NTU}$ \\
\hline Massa $(\mathrm{g})$ & 9,493 & 6,376 \\
\hline
\end{tabular}




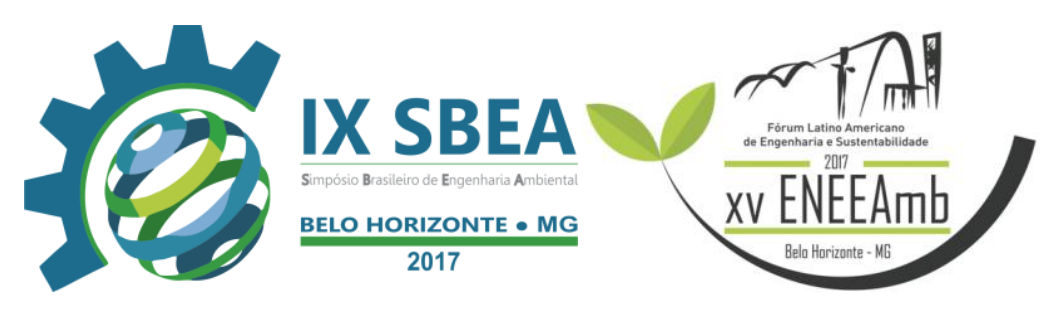

Para o parâmetro de turbidez ocorreu uma diminuição de 99,5\% e uma variação do $\mathrm{pH}$ comparado ao efluente bruto.

\subsection{VANTAGENS E DEVANTAGENS}

Segundo, Mollah et al. (2001) enumera as principais vantagens e desvantagens da técnica de eletrofloculação frente às técnicas tradicionais de tratamento de efluentes industriais:

\section{Vantagens:}

- Requer equipamentos simples e de fácil operação, em que a corrente e o potencial aplicado podem ser medidos e controlados de maneira automatizada.

- Há maior controle na liberação do agente coagulante, em comparação com os processos físico-químicos convencionais.

- As bolhas de gás produzidas durante a eletrólise levam o contaminante ao topo do reator, onde pode ser facilmente removido.

- A célula eletrolítica é eletricamente controlada, não necessitando de dispositivos adicionais, o que requer menos manutenção.

\section{Desvantagens:}

- Os eletrodos precisam ser substituídos regularmente, caso sofram passivação ou desgaste.

- O consumo de energia elétrica pode ser dispendioso em algumas regiões.

- Um filme de óxido impermeável pode ser formado no catodo, conduzindo a perda de eficiência da unidade.

- Requer alta condutividade do efluente.

\section{CONCLUSÕES/RECOMENDAÇÕES}

O resultado obtido após a filtração pode ser reutilizado para serviços de limpeza na indústria, mas provavelmente não poderá ser reutilizado no processo da lavagem do 


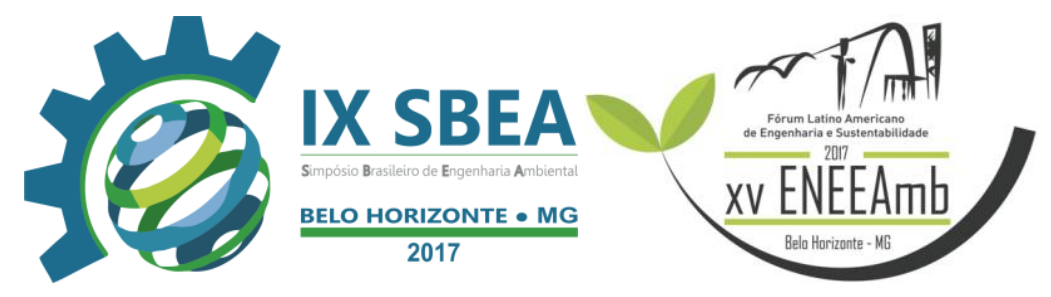

jeans, pois, poderá conter substâncias que possam reagir umas com as outras. Esse efluente não pode ser descartado na rede de esgoto, pois seu pH é alcalino entre 12 e 13. De acordo com o CONAMA resolução N430, de 13 de Maio de 2011 Art.16 para um efluente ser descartado na rede de esgoto deve possuir o $\mathrm{pH}$ entre 5 e 9.

Apesar de tudo, o experimento apresentou resultado satisfatório no que se refere à remoção dos particulados. Desta forma apresenta-se como um tratamento de alta qualidade, baixo custo de montagem e, se aplicado numa tensão maior terá um tempo de reação menor.

A quantidade de sal está relacionada com a eficiência do parâmetro cor, se adicionado uma maior quantidade de $\mathrm{NaCl}$ melhor e mais clara será a cor do efluente final.

\section{REFERÊNCIAS BIBLIOGRÁFICAS}

BRASIL 2005. Resolução CONAMA (Conselho Nacional de Meio Ambiente). Resolução n. ${ }^{\circ}$ 357, de 17 de Março de 2005. Dispõe sobre a classificação dos corpos de água e diretrizes ambientais para o seu enquadramento, bem como estabelece as condições e padrões de lançamento de efluentes, e dá outras providências. Diário Oficial da República Federativa do Brasil, Brasília, 2005.

CERQUEIRA, A. A. Aplicação da técnica de eletrofloculação no tratamento de efluentes têxteis. Rio de Janeiro, 111 p., 2006. Dissertação (Mestrado) - Universidade do Estado do Rio de Janeiro.

CERQUEIRA, A; RUSSO, C; MARQUES, M. R. C. Electroflocculation For Textile Wastewater Treatment. Brazilian Journal of Chemical Engineering, v.26, n.4, p.659668, 2009.

COUTO, M. G.; ALMEIDA, V. B.; MAINIER, F. B. Responsabilidade civil, penal e administrativa do auditor ambiental à luz do direito brasileiro. In: II Congresso Nacional em Excelência em Gestão, Niterói: Universidade Federal Fluminense, 2004. p. 8.

HASSEMER, M. E. N. Oxidação fotoquímica - Uv/H2O2 - para degradação de poluentes em efluentes da indústria têxtil. Florianópolis, 175 p., 2006. Tese (Doutorado) - Universidade Federal de Santa Catarina, Santa Catarina.

IMMICH, A. P. S. Remoção de corantes de efluentes têxteis utilizando folhas de Azadirachta indica como adsorvente. Florianópolis, 119 p., 2006. Dissertação (Mestrado) - Universidade Federal de Santa Catarina, Santa Catarina. 


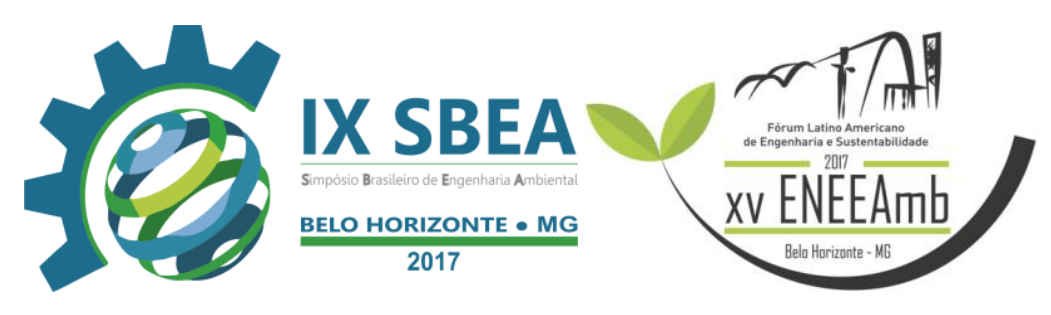

KUNZ, A; ZAMORA, P. P; MORAES, S. G; DURÁN, N. Novas Tendências no Tratamento de Efluentes Têxteis. Química Nova, São Paulo, v.25, n.1, p.78-82, 2002.

MELO, A. R. Otimização do reuso de água em lavadores contínuos da indústria têxtil. Florianópolis, 219 p., 2005. Dissertação (Mestrado) - Universidade Federal de Santa Catarina, Santa Catarina.

MOLLAH, M. A; SCHENNACH, R; PARGA, J. R; COCKE, D. L. Electroflocculation (EC) Science Andapplications. Journal of Hazardous Materials, v.84, n.1, p. 29-41, 2001.

MORAN, C; HALL, M. E; HOWELL, R. Effects of Sewage Treatment on Textile Effluent. Journal of the Society of Dyersand Colourists, 113, p. 272-274, 1997.

PASCHOAL, F. M. M; FILHO, G. T. Aplicação da tecnologia de eletrofloculação na recuperação do corante índigo blue a partir de efluentes industriais. Química Nova, São Paulo, vol.28, n.4, 2005.

SCHNEIDERS, D. Potencial de geração de biogás no tratamento de efluente e lodo têxtil em reator anaeróbio de fluxo ascendente e manta de lodo (UASB). 2011. Projeto de Qualificação (Mestrado em Engenharia Ambiental)-Universidade Regional de Blumenau, Blumenau, 2011.

TALARPOSHTI, A. M; DONNELLY, T; ANDERSON, G. K. Colour Removal From a Simulated Dye Wastewater Using a Twophase Anaerobic Packed Bed Reactor. Water Research, v.35, p. 425 - 432, 2001.

TOLEDO, R.A.S. Tecnologia da Reciclagem. Química Têxtil, São Paulo: Editora Futura, 1996. 8-14 p.

THEBALDI, M. S; Sandri, D; FELISBERTO, A. B; ROCHA, M. S; NETO, S. A. Qualidade da água de um córrego sob influência de efluente tratado de abate bovino. Revista Brasileira de Engenharia Agrícola e Ambiental, Campina Grande, v.15, n.3, p.302 - 309, 2011. 